\title{
An Instrument for Estimating the 6-Month Survival Probability After Whole-brain Irradiation Alone for Cerebral Metastases from Gynecological Cancer
}

\author{
STEFAN JANSSEN ${ }^{1,2}$, HEINKE C. HANSEN ${ }^{1}$, STEVEN E. SCHILD ${ }^{3}$ and DIRK RADES ${ }^{1}$ \\ ${ }^{1}$ Department of Radiation Oncology, University of Lübeck, Lübeck, Germany; \\ ${ }^{2}$ Private Practice of Radiation Oncology, Hannover, Germany; \\ ${ }^{3}$ Department of Radiation Oncology, Mayo Clinic, Scottsdale, AZ, U.S.A.
}

\begin{abstract}
Background/Aim: Patients with cerebral metastases from gynecological cancer who receive wholebrain irradiation (WBI) alone require personalized therapy. This study contributes to personalized care by creating an instrument to predict 6-month survival probability. Patients and Methods: In 49 patients, six pre-treatment variables, namely age, Eastern Cooperative Oncology Group performance score (ECOG-PS), primary tumor type, number of cerebral metastases, metastasis outside the brain, and interval between diagnosis of gynecological cancer and WBI, were analyzed for survival. Results: Of the six pre-treatment variables, ECOG-PS was significantly associated with survival $(p=0.014)$ and metastasis outside the brain showed $a$ trend for association $(p=0.096)$. Six-month survival rates divided by 10 resulted in scores of 0,2 or 7 points for ECOG-PS and of 2 or 7 points for metastasis outside the brain. Scores for individual patients were 2, 4, 7, 9 or 14 points. Three groups were created, those with 2-7, 9 and 14 points, with 6-month survival rates of 10\%, 53\% and 100\%, respectively ( $p=0.004)$. Conclusion: An instrument was designed to predict the 6-month survival of patients receiving WBI for cerebral metastases from gynecological cancer and facilitate personalized care.
\end{abstract}

Many patients with cerebral metastases from gynecological cancer are not candidates for local therapies such neurosurgical resection and stereotactic radiosurgery due to their having too many cerebral lesions, a poor performance

Correspondence to: Professor Dirk Rades, MD, Department of Radiation Oncology, University of Lübeck, Lübeck, Ratzeburger Allee 160, 23562 Lübeck, Germany. Tel: +49 45150045401, Fax: +4945150045404, e-mail: rades.dirk@gmx.net

Key Words: Whole-brain irradiation, brain metastases, gynecological cancer, 6-month survival probability, prognostic instrument. status, or many comorbidities (1). Therefore, the majority of these patients receive whole-brain irradiation (WBI) alone.

Several dose-fractionation regimens are available for WBI, including short-course programs such as $5 \times 4$ Gy in 1 week or longer-course programs with doses of 2 to 3 Gy per fraction lasting 2 to 4 weeks.

It has been reported for patients with cerebral metastases from a variety of solid tumors that intracerebral control and survival were no worse in those with poor prognoses after $5 \times 4$ Gy than after longer-course WBI (2). Therefore, shortcourse WBI is recommended for patients with a short survival time in order to avoid spending many of their remaining days receiving radiotherapy. According to the results of a previous study, longer-course WBI with total doses greater than $30 \mathrm{~Gy}$ and doses of less than 3 Gy per fraction resulted in improved intracerebral control and survival in patients with a longer expected remaining lifespan (3). Moreover, it has been reported that using doses of less than $3 \mathrm{~Gy}$ per fraction led to less pronounced neurocognitive deficits $(4,5)$. Therefore, for patients with longer expected survival times, longer-course WBI programs appear more appropriate. The results of those previous studies demonstrate the importance of estimating a patient's remaining lifespan as precisely as possible in order to choose the appropriate WBI regimen, ideally with the help of prognostic instruments (survival scores). This study aimed to create a prognostic instrument that helps predict the 6month survival probability particularly for patients receiving WBI alone for cerebral metastases from gynecological cancer.

\section{Patients and Methods}

Data of 49 patients treated with WBI alone for cerebral metastases from gynecological cancer between 1988 and 2017 were retrospectively evaluated. Dose-fractionation regimens included shorter-course WBI with $5 \times 4$ Gy in 1 week $(n=16)$, longer-course WBI with $10 \times 3$ Gy in 2 weeks $(n=18)$ and other longer-course WBI programs $(n=15)$. The dose-fractionation regimen $(5 \times 4$ Gy $v s$. longer-course programs) and six pre-treatment variables were 
analyzed for possible associations with survival. These variables included age ( $\leq 59 v s . \geq 60$ years, median age $=59$ years $)$, Eastern Cooperative Oncology Group performance score (ECOG-PS) (0-1 vs. 2 vs. 3), type of primary tumor (ovarian vs. uterine vs. cervical $v s$. vaginal/vulvar cancer), number of cerebral metastases (1-3 vs. $\geq 4$ ), metastasis outside the brain (no $v s$. yes) and the interval between first diagnosis of the gynecological cancer and WBI $(\leq 24$ $v s . \geq 25$ months, median interval=24 months). The distribution of patients according to all seven variables is summarized in Table I.

Statistical methods included the Kaplan-Meier method and the log-rank test for univariate analyses (6). Variables with a $p$-value of less than 0.05 were regarded significant and additionally included in a multivariate analysis, which was performed with the Cox proportional hazards model. Those pre-treatment variables that were significant $(p<0.05)$ or showed a trend $(p<0.10)$ for association in the multivariate analysis were used to create the prognostic instrument.

\section{Results}

On univariate analyses, the dose-fractionation regimen of WBI $(p=0.041)$, ECOG-PS $(p=0.001)$ and metastasis outside the brain $(p=0.017)$ were significantly associated with survival (Table II) and were, therefore, included in the analysis with the Cox proportional hazards model. In this multivariate analysis, the ECOG-PS (hazard ratio $(\mathrm{HR})=1.97$, 95\% confidence interval $(\mathrm{CI})=1.15-3.37, p=0.014)$ was significantly associated with survival. In addition, metastasis outside the brain showed a trend for association $(\mathrm{HR}=2.00$, 95\% CI=0.89-5.12, $p=0.096)$. The dose-fractionation regimen of WBI was not significant in the multivariate analysis $(\mathrm{HR}=1.58,95 \% \mathrm{CI}=0.80-3.35, p=0.195)$. Therefore, ECOG-PS and metastasis outside the brain were used to create the prognostic instrument for estimating the 6-month survival probability.

The instrument was based on the incorporation of these two variables by dividing the 6-month percentage survival rates by 10 (Table III). The score from the ECOG-PS and the extracranial metastases were then summed into a single prognostic score for each patient. This procedure resulted in prognostic scores of 2, 4, 7, 9 or 14 points. The corresponding 6-month survival rates were $0 \%, 14 \%, 0 \%, 53 \%$ and $100 \%$, respectively $(p<0.001)$. Based on these scores, three prognostic groups were created, namely 2-7 points, 9 points and 14 points. The 6-month survival rates of these groups were significantly different at $10 \%, 53 \%$ and $100 \%$, respectively $(p=0.004)$, and median survival times were 4,7 and 9 months, respectively.

\section{Discussion}

Despite considerable research efforts in the field of metastatic gynecological cancer, many of these patients have a poor prognosis, especially in those with multiple brain metastases requiring WBI. Better outcomes may be achieved
Table I. Distributions of the investigated seven variables.

\begin{tabular}{lc}
\hline Factor & Number of patients $(\%)$ \\
\hline Dose-fractionation regimen of WBI & \\
$5 \times 4$ Gy in 1 week & $16(33)$ \\
Longer-course programs & $33(67)$ \\
Age at the time of WBI & \\
$\leq 59$ Years & $25(51)$ \\
$\geq 60$ Years & $24(49)$ \\
ECOG performance score & $15(31)$ \\
$0-1$ & $27(55)$ \\
2 & $7(14)$ \\
3 & \\
Primary tumor type & $26(53)$ \\
Ovarian cancer & $13(27)$ \\
Uterine cancer & $8(16)$ \\
Cervix cancer & $2(4)$ \\
Vaginal/vulvar cancer & \\
Number of cerebral metastases & $13(27)$ \\
$1-3$ & $36(73)$ \\
$\geq 4$ & $11(22)$ \\
Metastases outside the brain & $38(78)$ \\
No & \\
Yes & \\
Interval between first diagnosis of the & \\
gynecological cancer and WBI & $25(51)$ \\
$\leq 24$ Months & $24(49)$ \\
$\geq 25$ Months & \\
\hline
\end{tabular}

WBI: Whole-brain irradiation, ECOG: Eastern Cooperative Oncology Group.

with the implementation of novel anticancer drugs (7). However, personalized cancer care can contribute to this ambitious goal. Personalized approaches consider many aspects of a patient's specific situation and preferences. One important aspect is the patient's survival prognosis. If it is quite poor, the treatment should not be long or burdensome. If it is favorable, therapy should aim to achieve the best possible long-term disease control with acceptable late toxicities.

These considerations also apply to patients who are assigned to WBI alone for cerebral metastases from gynecological cancer. In the case of a short remaining lifespan, a short course of WBI is preferable. In a large retrospective study performed on 416 patients with cerebral metastases from various tumor types and poor survival prognoses, standard WBI with $10 \times 3$ Gy in 2 weeks was as effective as higher dose, longer regimens $(15 \times 3$ Gy in 3 weeks $/ 20 \times 2$ Gy in 4 weeks) with respect to intracerebral control and survival (8). The 6-month intracerebral control rates were $39 \%$ after $10 \times 3$ Gy and $41 \%$ after higher doses, respectively $(p=0.61)$, and the 6 -month survival rates $33 \%$ and $29 \%$, respectively $(p=0.86)$. It was possible to reduce overall treatment time by $50 \%$ from 4 to 2 weeks without 
Table II. Survival rates at 6 months following whole-brain irradiation (WBI) on univariate analyses.

\begin{tabular}{lcc}
\hline Factor & $\begin{array}{c}\text { Survival at } \\
6 \text { months }(\%)\end{array}$ & $p$-Value \\
& & \\
\hline Dose-fractionation regimen of WBI & 44 & \\
$5 \times 4$ Gy in 1 week & 27 & $\mathbf{0 . 0 4 1}$ \\
Longer-course programs & & \\
Age at the time of WBI & 44 & 0.074 \\
$\quad 55$ Years & 21 & \\
$\geq 60$ Years & & \\
ECOG performance score & 67 & \\
$0-1$ & 22 & \\
2 & 0 & \\
3 & & \\
Primary tumor type & 35 & \\
Ovarian cancer & 23 & \\
Uterine cancer & 50 & \\
Cervix cancer & 0 & \\
Vaginal/vulvar cancer & & \\
Number of cerebral metastases & 46 & \\
$1-3$ & 28 & 0.565 \\
$\geq 4$ & & \\
Metastases outside the brain & 73 & \\
No & 21 & \\
Yes & & \\
Interval between first diagnosis of the & 32 & \\
gynecological cancer and WBI & & \\
$\leq 24$ Months & & \\
$\geq 25$ Months & & \\
\hline
\end{tabular}

ECOG: Eastern Cooperative Oncology Group. Bold: Significant $p$-values.

loss of efficacy. In another large retrospective study in a similar patient population $(\mathrm{n}=442)$, short-course WBI with $5 \times 4$ Gy in 1 week was not inferior to $10 \times 3$ Gy in 2 weeks (2). Six-month intracerebral control rates were $50 \%$ after $5 \times 4$ Gy and $37 \%$ after $10 \times 3 \mathrm{~Gy}$, respectively $(p=0.07)$, and 6 month survival rates were $24 \%$ and $27 \%$, respectively $(p=0.29)$. Thus, the overall treatment time was further reduced to only 1 week. In contrast, patients with a more favorable survival prognosis can benefit from longer-course WBI in terms of improved intracerebral control and survival (3). Moreover, doses per fraction of less than $3 \mathrm{~Gy}$ were reported to be associated with less neurocognitive decline than doses of $3 \mathrm{~Gy}$ and more per fraction $(4,5)$.

Since a patient's survival time is an important factor to be considered when selecting the appropriate WBI regimen, it would be helpful if the treating radiation oncologists were able to estimate a specific patient's prognosis, ideally with a simple instrument. Several such instruments are already available for patients with cerebral metastases from specific tumor types such as breast cancer, lung cancer and others (913). In the present study, an additional prognostic instrument was developed particularly for patients treated with WBI
Table III. Scoring points obtained by dividing the 6-month survival rates (in \%) by 10

\begin{tabular}{lcc}
\hline & $\begin{array}{c}\text { Survival at } \\
6 \text { months }(\%)\end{array}$ & $\begin{array}{c}\text { Scoring } \\
\text { points }\end{array}$ \\
\hline ECOG performance score & & \\
$0-1$ & 67 & 7 \\
2 & 22 & 0 \\
3 & 0 & 7 \\
Metastasis outside the brain & 73 & 2 \\
No & 21 & \\
Yes & & \\
\hline
\end{tabular}

ECOG: Eastern Cooperative Oncology Group.

alone for cerebral metastases from gynecological cancer. Since only patients treated with WBI alone were included, this score is more specific and carries less risk of hidden selection bias due to different treatment approaches than a previous instrument that also included patients receiving local modalities for cerebral metastases from gynecological cancer (14). In the present study, three prognostic groups were designated based on two variables, namely ECOG-PS and metastasis outside the brain: 2-7 points, 9 points and 14 points. The 6-month survival rate in the 2-7 points group was only $10 \%$. Therefore, these patients appear to be good candidates for short-course WBI, for example with $5 \times 4$ Gy in 1 week. For the other two groups (9 points and 14 points), the 6-month survival rates were much more favorable, at $53 \%$ and $100 \%$, respectively. Patients of both groups appear appropriate for treatment with longer-course WBI. Patients of the group with 9 points may receive $10 \times 3$ Gy in 2 weeks, and patients of that with 14 points may receive longer-course WBI with total doses $>30$ Gy and doses per fraction $<3 \mathrm{~Gy}$.

However, when considering these suggestions, the retrospective nature of the study and the risk of hidden selection biases must be considered. In order to further reduce the risk of WBI-related neurocognitive decline, WBI may be performed with hippocampal-sparing for selected patients with a limited number of cerebral lesions that are not close to the hippocampi (15).

In conclusion, a new instrument was designed to predict the 6-month survival probability of patients receiving WBI for cerebral metastases from gynecological cancer. Three predictive groups were created with significantly different survival prognoses, facilitating more personalized treatment in this specific patient group.

\section{Conflicts of Interest}

On behalf of all Authors, the corresponding Author states that there is no conflict of interest related to this study. 


\section{References}

1 Tsao MN, Rades D, Wirth A, Lo SS, Danielson BL, Gaspar LE, Sperduto PW, Vogelbaum MA, Radawski JD, Wang JZ, Gillin MT, Mohideen N, Hahn CA and Chang EL: Radiotherapeutic and surgical management for newly diagnosed brain metastasis(es): An American Society for Radiation Oncology evidence-based guideline. Pract Radiat Oncol 2: 210-225, 2012.

2 Rades D, Kieckebusch S, Lohynska R, Veninga T, Stalpers LJ, Dunst $\mathrm{J}$ and Schild SE: Reduction of overall treatment time in patients irradiated for more than three brain metastases. Int J Radiat Oncol Biol Phys 69: 1509-1513, 2007.

3 Rades D, Panzner A, Dziggel L, Haatanen T, Lohynska R and Schild SE: Dose-escalation of whole-brain radiotherapy for brain metastasis in patients with a favorable survival prognosis. Cancer 118: 3853-3859, 2012.

4 DeAngelis LM, Delattre JY and Posner JB: Radiation-induced dementia in patients cured of brain metastases. Neurology 39: 789-796, 1989.

5 Shaw MG and Ball DL: Treatment of brain metastases in lung cancer: strategies to avoid/reduce late complications of whole brain radiation therapy. Curr Treat Options Oncol 14: 553-567, 2013.

6 Kaplan EL and Meier P: Non-parametric estimation from incomplete observations. J Am Stat Assoc 53: 457-481, 1958.

7 Gadducci A and Guerrieri ME: Immune checkpoint inhibitors in gynecological cancers: Update of literature and perspectives of clinical tesearch. Anticancer Res 37: 5955-5965, 2017.

8 Rades D, Haatanen T, Schild SE and Dunst J: Dose escalation beyond 30 Grays in 10 fractions for patients with multiple brain metastases. Cancer 110: 1345-1350, 2007.

9 Sehmisch L, Schild SE and Rades D: Development of a survival score for patients with cerebral metastases from melanoma. Anticancer Res 37: 249-252, 2017.
10 Rades D, Dziggel L, Segedin B, Oblak I, Nagy V, Marita A and Schild SE: The first survival score for patients with brain metastases from small cell lung cancer (SCLC). Clin Neurol Neurosurg 115: 2029-2032, 2013.

11 Rades D, Dziggel L, Segedin B, Oblak I, Nagy V, Marita A, Schild SE, Trang NT and Khoa MT: A new survival score for patients with brain metastases from non-small cell lung cancer. Strahlenther Onkol 189: 777-781, 2013.

12 Rades D, Dziggel L, Segedin B, Oblak I, Nagy V, Marita A, Schild SE, Trang NT and Khoa MT: A simple survival score for patients with brain metastases from breast cancer. Strahlenther Onkol 189: 664-667, 2013.

13 Rades D, Dziggel L, Veninga T, Bajrovic A and Schild SE: Overall survival after whole-brain radiation therapy for intracerebral metastases from testicular cancer. Anticancer Res 36: 4817-4819, 2016.

14 Rades D, Janssen S, Bajrovic A, Veninga T, Fischer D and Schild SE: A new scoring tool to assess overall survival in patients with intracerebral metastases from gynecological cancers. Int J Gynecol Cancer 27: 597-602, 2017.

15 Gondi V, Pugh SL, Tome WA, Caine C, Corn B, Kanner A, Rowley H, Kundapur V, DeNittis A, Greenspoon JN, Konski AA, Bauman GS, Shah S, Shi W, Wendland M, Kachnic L and Mehta MP: Preservation of memory with conformal avoidance of the hippocampal neural stem-cell compartment during wholebrain radiotherapy for brain metastases (RTOG 0933): a phase II multi-institutional trial. J Clin Oncol 32: 3810-3816, 2014.

Received April 18, 2018

Revised May 11, 2018

Accepted May 15, 2018 